\title{
PENGEMBANGAN KEPUASAN KERJA KARYAWAN YANG DITINJAU DARI KEBIJAKAN KOMPENSASI DAN SISTEM PENGEMBANGAN KARIR
}

\author{
Misbachul Munir \\ Universitas Sunan Giri Surabaya
}

Fayola Issalillah

Universitas Negeri Islam Maulana Malik Ibrahim Malang

\section{Didit Darmawan}

Universitas Mayjen Sungkono

\section{Ella Anastasya Sinambela}

Universitas Mayjen Sungkono

eas.sinambela@gmail.com

\section{Rahayu Mardikaningsih}

Universitas Mayjen Sungkono

\begin{abstract}
Abstrak The dynamics of HR management that continues to increase now should encourage management in every organization to change the pattern of HR management. Management needs to make efforts to maintain and improve their human resources. One of them is by creating employee job satisfaction. The purpose of this study is to determine the role of compensation and career development in employee job satisfaction. In this study, 46 respondents were used as a sample, which was carried out using the census technique. The analysis uses descriptive analysis and inferential analysis, multiple linear regression. The results show that employee job satisfaction is partially and simultaneously influenced by compensation and career development.
\end{abstract}

Kata Kunci compensation, career development, job satisfaction

\section{PENDAHULUAN}

Dinamika pengelolaan sumber daya manusia (SDM) yang terus meningkat sekarang seharusnya mendorong manajemen di setiap organisasi untuk mengubah pola pengelolaan sumber daya manusianya. Dinamika ini seharusnya mampu mengubah pandangan bahwa SDM bukan lagi sekadar tenaga manusia. Namun, SDM harus dilihat sebagai kontributor utama keberhasilan setiap program atau kegiatan di organisasi yang berdaya dan berkompetensi. Untuk mencapai tujuan organisasi perlu melakukan berbagai upaya untuk berinvestasi di sektor SDM. Untuk menjaga daya saing, SDM dalam organisasi harus senantiasa mengembangkan pengetahuan dan keterampilannya. Upaya yang tidak kalah pentingnya adalah bagaimana organisasi memelihara pemeliharaan agar staf SDM yang memiliki kompetensi, keterampilan, pengetahuan, dan sikap yang dibutuhkan organisasi tetap berkomitmen untuk menginvestasikan brainpower yang 
dimilikinya dan mengurangi keinginan untuk berpindah kerja. Di organisasi swasta, karyawan tanpa henti dapat mencari organisasi lain yang dianggap memberikan nilai lebih untuk kemudian meninggalkan organisasi tersebut dan pindah ke organisasi lain atau bahkan mungkin memutuskan untuk berhenti bekerja sama sekali. Berbagai upaya yang dilakukan oleh suatu organisasi untuk mempertahankan karyawannya dalam praktik manajemen sumber daya manusia. Kepuasan kerja harus tercapai bagi semua karyawan agar tetap bertahan bersama organisasi.

Adanya kepuasan kerja pada diri seorang karyawan antara lain disebabkan oleh bentuk pengembangan karir dan kompensasi yang memuaskan yang diterima karyawan dari organisasi. Pada prinsipnya organisasi memberikan karyawan kompensasi atas pekerjaan mereka. Kompensasi tersebut tidak hanya gaji yang diberikan tetapi fasilitas lain yang mendukung pekerjaan tersebut. Arifin et al (2019) menjelaskan perlu adanya kompensasi lebih apabila karyawan tersebut telah memberikan kontribusi yang baik pada pelaksanaan jalanya sebuah organisasi. Dengan adanya kompensasi yang sesuai dengan kerja yang dilakukan akan memberikan motivasi bagi karyawan untuk selalu memberikan yang terbaik pada organisasi sebagai dampak dari kepuasan kerja yang ditimbulkan.

Dengan adanya kompensasi yang sesuai karyawan juga memerlukan adanya pengembangan karir pada perusahaan tersebut. Perencanaan karir karyawan juga mampu membuat karyawan tersebut bertahan pada suatu organsiasi. Dengan memiliki perencanaan karir yang baik dan sesuai bagi karyawan maka karyawan tidak akan melihat posisi pada perusahaan lain (Al Hakim et al., 2019). Hal ini disebabkan karyawan telah memiliki rasa puas pada organisasinya saat ini.

Dengan kepuasan karyawan yang baik maka kinerja karyawan akan berjalan selaras (Mardikaningsih, 2014). Sinambela (2020) menjelaskan pentingnya untuk meningkatkan kepuasan kerja karyawan untuk hasil kerja yang lebih baik. Fokus studi ini mengarah kepada kepuasan kerja yang ditentukan oleh kebijakan pengembangan karir serta penetapan kompensasi.

\section{LANDASAN TEORI}

Muhammad et al. (2016) menunjukkan hubungan yang dimiliki oleh kompensasi serta kepuasan kerja dan membandingkan dampak kompensasi antara karyawan di sektor publik dan swasta. Kompensasi dianggap sebagai motivator utama untuk kepuasan kerja dan kinerja karyawan. Besarnya kompensasi yang dianggap kurang kompetitif di sektor publik dibandingkan dengan nilai yang diberikan kepada sektor swasta merupakan salah satu alasan sektor publik lebih sulit untuk mendapatkan dan mempertahankan karyawan yang cakap dibandingkan sektor swasta. Dessler (2015) menyatakan bahwa organisasi yang dapat memenangkan employee engagement dalam bentuk komitmen organisasional adalah organisasi yang dapat menyediakan kebutuhan pengembangan karir karyawannya dalam jangka panjang. Lebih lanjut dikatakan bahwa cara terbaik untuk mencapai komitmen karyawan adalah dengan memberikan lebih banyak waktu dan perhatian terhadap kebutuhan karyawan untuk mencapai tahapan pencapaian karirnya (Dessler, 2015). Praveena et al. (2017) mengungkapkan bahwa kompensasi merupakan komponen dasar untuk mengelola dan mempertahankan karyawan terbaik. Kompensasi memiliki peran utama dalam mempengaruhi komitmen organisasi karyawan, yang membuat karyawan tetap bertahan pada pekerjaannya. Sedangkan kepuasan kerja dipengaruhi juga oleh kompensasi. Besaran kompensasi harus berbanding lurus dengan kualifikasi, keterampilan, pengetahuan, dan kinerja karyawan. Beberapa penelitian lain menunjukkan pengaruh langsung kompensasi pada kepuasan kerja, sesuai dengan yang ditemukan oleh 
Salisu et al. (2015). Keterkaitan antara kompensasi dan kepuasan kerja telah dibuktikan oleh Ghazzawi (2008) yang mencoba menggali apa saja yang mampu menciptakan ketidak puasan kerja pada karyawan atau kepuasan kerja karyawan. Dalam penelitiannya, Ghazzawi telah membuktikan determinan yang berpengaruh terhadap kepuasan kerja tentu saja gaji. Hal yang sama dibuktikan dalam penelitian lain yang menyatakan bahwa seorang pekerja akan merasa lebih puas di tempat kerja ketika ia mendapatkan hasil pekerjaan (dalam bentuk uang) yang lebih tinggi daripada karyawan lain yang hasil pekerjaannya lebih rendah (George \& Jones, 2008). Studi dari Darmawan (2015) menyatakan bahwa kompensasi telah terbukti memberikan peran terhadap kepuasan karyawan dalam bekerja. Hal ini menjadi dasar bahwa hipotesis penelitian ini merupakan kompensasi memiliki peran pada pembentukan kepuasan kerja karyawan.

Bernardin \& Russell (2013) menjelaskan bahwa sistem pengembangan karir merupakan bentuk upaya untuk menyeimbangkan kebutuhan karir individu dan tenaga kerja yang dibutuhkan oleh organisasi. Studi Saleem (2013) yang membuktikan bahwa pengaruh pengembangan karir akan lebih optimal dengan dukungan perencanaan karir yang baik dari setiap karyawan dan dukungan manajemen karir yang baik dari organisasi. Keduanya merupakan anteseden yang terbukti mempunyai kontribusi pembentukan pengembangan sistem karir. Dalam pengembangan karir, dukungan yang diberikan oleh atasan dan organisasi merupakan poin penting lainnya selain keinginan untuk maju dari karyawan itu sendiri. Pengelolaan pengembangan karir karyawan yang baik akan memberikan potensi kenaikan kinerja individu secara signifikan. Karyawan yang memiliki rasa puas dari pekerjaannya akan memberikan umpan balik kepada organisasi dengan meningkatkan produktivitas kerjanya, memberikan pelayanan, dan mencapai target yang memuaskan. Kaya dan Ceylan (2014) menunjukkan peningkatan kepuasan yang dirasakan pekerja, ditentukan langsung dan positif dari faktor pengembangan karir. Penelitian ini menunjukkan bahwa gaji tidak terlalu penting dalam komitmen organisasi. Adanya lingkungan kerja yang nyaman dan modal kehidupan sosial yang harmonis, serta kepercayaan yang diberikan organisasi kepada karyawannya, dianggap lebih berharga daripada uang. Hal ini menjadi dasar dari hipotesis penelitian yang tersebut bahwa adanya sistem pengembangan karir akan berperan terhadap pembentukan kepuasan kerja. Selain itu diperkuat juga dengan studi dari Al Hakim et al. (2019).

\section{METODOLOGI PENELITIAN}

Studi ini mengamati kepuasan kerja di lingkungan kerja. Teknik survei dengan media kuesioner. Karyawan di sebuah perusahaan di Kota Sidoarjo tertunjuk sebagai populasi. Agar penelitian dapat dilakukan lebih efektif, maka diambil batasan populasi berupa kriteria tertentu. Kriteria tersebut adalah a) karyawan telah bekerja setidaknya setahun lebih ; dan b) pendidikan terakhir di tingkat sekolah menengah atas atau sederajat. Populasi dengan kriteria tersebut adalah 46 orang. Metode pengambilan sampel adalah sensus.

Alat analisis ada dua bentuk, yang pertama secara deskriptif kemudian yang kedua merupakan analisis inferensial. Analisis deskriptif merupakan analisis yang berhubungan dengan pengumpulan dan penyajian data yang bersifat deskriptif sehingga saat data disajikan, pembaca mampy memahami data tersebut dengan jelas. Analisis inferensial digunakan agar mampu menjawab pertanyaan pada penelitian yang dilakukan dan mampu menyimpulkan mengenai data yang didapatkan dari sampel untuk digunakan pada penelitian (Sekaran 2003) Analisis deskriptif dilakukan dengan menyajikan frekuensi dan persentase karakteristik responden, serta dengan menafsirkan sikap atau tanggapan 
responden responden yang disampaikan melalui jawaban kuesioner. Analisis inferensial adalah dilakukan dengan menggunakan regresi linier berganda.

Studi melibatkan variabel bebas yang pertama adalah kompensasi. Kompensasi menurut Arifin et al. (2019) merupakan pemberian yang dilakukan perusahaan sebagai balasan dari kerja yang dilakukan oleh karyawan. Kompensasi memiliki 4 dimensi menurut Darmawan (2011) yaitu 1) gaji 2) fasilitas kerja; 3) fasilitas luar kerja; 4) uang lembur. Variabel bebas kedua pada penelitian ini adalah pengembangan karir. Pengembangan karir merupakan sistem yang diciptakan perusahaan untuk merencanakan karir karyawan. Dimensi pengembangan karir menurut Al Hakim et al. (2019) adalah sebagai berikut 1) promosi jabatan; 2) mutasi; 3) pelatihan; 4) pendidikan. Selanjutnya kepuasan kerja merupakan variabel terikat. Kepuasan kerja menurut Darmawan dan Mardikaningsih (2021) merupakan sikap seorang karyawan yang positif pada pekerjaannya. Terdapat dimensi kepuasan kerja karyawan menurut Sinambela (2014) yaitu 1) merasa senang dengan pekerjaannya; 2) selalu berusaha melakukan yang terbaik pada perusahaanya; 3 ) memberikan metode pada penyelesaian perusahaan.

\section{HASIL PENELITIAN}

Responden penelitian ini berjumlah 46 responden dengan mayoritas adalah lakilaki dengan jumlah 27 responden dan wanita sebanyak 19 responden. Berdasarkan lama bekerja, mayoritas responden bekerja selama 1-3 tahun yaitu 21 responden atau 45,6\%. Selanjutnya mayoritas responden merupakan lulusan SMA yaitu sebanyak 56,5\%.

Pada data penelitian dicek dulu dengan kelayakan validitas dan reliabilitas. Validitas memperlihatkan semua pernyataan pada kuisioner yang disebar dinyatakan valid. Untuk uji reliabilitas nilai Cronbach Alpha yang didapatkan melebihi 0,6. Ini membutkikan variabel dinyatakan berkualitas dan andal.

Uji normalitas dilakukan untuk menguji data penelitian yang digunakan. Hasil ini ditunjukkan pada Gambar 1. Terlihat data menyebar disekitar garis utama diagonal. Ini membuktikan data yang diperoleh telah berdistribusi normal.

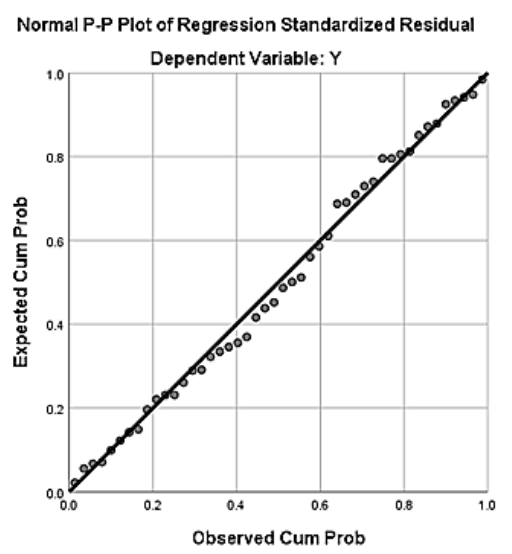

Gambar 1. Normal probability plot

Uji autokorelasi dengan berpedoman nilai dari Durbin Watson. Nilai DW diperoleh dari analisis yang dilakukan yaitu sebesar 0,724. Dengan hasil ini maka dinyatakan bebas autokorelasi karena DW sesuai batas nilai yaitu berada diantara nilai negatif dua sampai positif dua. Uji multikolinearitas diperoleh VIF 0,913 serta tolerance 1,095. Dari hasil ini menunjukkan data penelitian tidak mengalami multikolinearitas. 
Uji heteroskedastisitas penelitian ini dilakukan dengan memperhatikan sebaran data pada scatterplot yang disajikan pada Gambar 2. Dari hasil ini dapat dinyatakan bahwa data tidak mengalami heteroskedastisitas. Hasil ini dibuktikan dengan titik data tersebear pada Y dan tidak membentuk pola tertentu. Dengan hasil yang diperoleh pada uji asumsi klasik maka penelitian dapat dilanjutkan pada uji regresi.

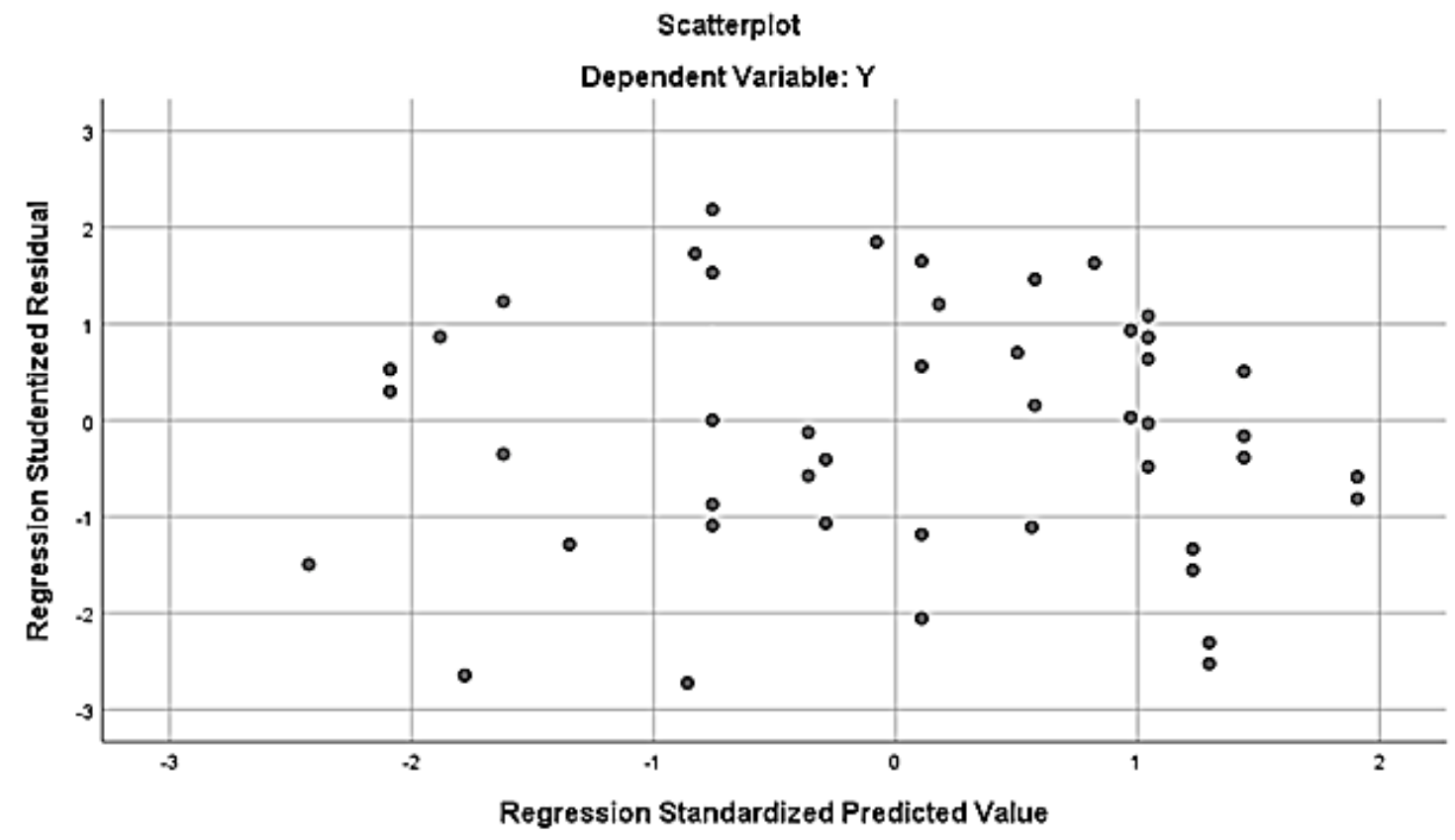

Gambar 2. Uji Heteroskedastisitas

Uji regresi dimulai dari uji t. Hasil di Tabel 1. Batas nilai yang digunakan adalah di bawah 5\% dan diperoleh nilai signifikan yang diperoleh oleh kompensasi (X.1) adalah 0,000. Hasil ini menunjukkan peran kompensasi pada kepuasan kerja punya dampak nyata. Hasil yang diperoleh peningkatan karir (X.2). Variabel peningkatan karir (X.2) memperoleh nilai signifikan 0,014. Hasil ini membuktikan bahwa kepuasan karyawan dipengaruhi oleh peningkatan karir secara parsial.

Dari tabel 1 didapatkan model regresi yaitu $\mathrm{Y}=30,187+3,438 X .1+1,862 X .2$. Hasil ini menunjukkan bahwa kepuasan kerja karyawan bernilai 30,187 apabila nilai kompensasi dan pengembangan karir bernilai nol.

Tabel 1

Coefficients $^{a}$

\begin{tabular}{|c|c|c|c|c|c|c|c|c|}
\hline & & \multicolumn{2}{|c|}{$\begin{array}{c}\text { Unstandardized } \\
\text { Coefficients }\end{array}$} & \multirow{2}{*}{\begin{tabular}{|c|}
$\begin{array}{c}\text { Standardized } \\
\text { Coefficients }\end{array}$ \\
Beta \\
\end{tabular}} & \multirow[b]{2}{*}{$\mathrm{t}$} & \multirow[b]{2}{*}{ Sig. } & \multicolumn{2}{|c|}{$\begin{array}{c}\text { Collinearity } \\
\text { Statistics }\end{array}$} \\
\hline \multicolumn{2}{|c|}{ Model } & B & Std. Error & & & & Tolerance & VIF \\
\hline \multirow[t]{3}{*}{1} & (Constant) & 30.187 & 6.127 & & 4.927 & .000 & & \\
\hline & X.1 & 3.438 & .831 & .497 & 4.137 & .000 & .913 & 1.095 \\
\hline & $\mathrm{X} .2$ & 1.862 & .726 & .308 & 2.566 & .014 & .913 & 1.095 \\
\hline
\end{tabular}

Selanjutnya dilakukan uji $\mathrm{F}$ untuk mengukur peran varibel bebas penelitian pada varibael terikat secara simultan. Tabel 2 didapatkan hasil $\mathrm{F}$ sebesar16,399 dengan nilai 
signifikan yang didapatkan yakni 0,000. Kompensasi dan pengembangan karir punya peran secara simultan dan signifikan pada kepuasan kerja karyawan.

Tabel 2

ANOVA $^{\mathrm{a}}$

\begin{tabular}{|l|l|r|r|r|r|r|}
\hline \multicolumn{2}{|l|}{ Model } & \multicolumn{1}{c|}{$\begin{array}{l}\text { Sum of } \\
\text { Squares }\end{array}$} & df & Mean Square & \multicolumn{1}{c|}{ F } & \multicolumn{1}{c|}{ Sig. } \\
\hline \multirow{4}{*}{1} & Regression & 712.230 & 2 & 356.115 & 16.399 & $.000^{\mathrm{b}}$ \\
\cline { 2 - 8 } & Residual & 933.770 & 43 & 21.716 & & \\
\cline { 2 - 8 } & Total & 1646.000 & 45 & & & \\
\hline
\end{tabular}

Selanjutnya dilakukan uji koefisien determinasi. Tabel 3 ada nilai $\mathrm{R}$ yang diperoleh sebesar 6,58 dan didapatkan nilai determinasi 0,433. Hasil ini menyatakan kepuasan kerja dipengaruhi sebesar 43,3\%. Untuk hal yang yang tidak diteliti di studi ini memiliki kontribusi sisanya.

Tabel 3

Model Summary ${ }^{\mathbf{b}}$

\begin{tabular}{|l|r|r|r|r|r|}
\hline Model & R & R Square & \multicolumn{1}{c|}{$\begin{array}{c}\text { Adjusted R } \\
\text { Square }\end{array}$} & $\begin{array}{c}\text { Std. Error of the } \\
\text { Estimate }\end{array}$ & Durbin-Watson \\
\hline 1 & $.658^{\mathrm{a}}$ & .433 & .406 & 4.660 & .724 \\
\hline
\end{tabular}

Temuan studi menunjukkan ada kompensasi dan kepuasan kerja terhubung secara nyata, maka dapat dikatakan ketika karyawan puas saat kompensasi seperti diharapkan dan diberikan organisasi. Mondy dan Noe (2005) menyatakan bahwa dari sisi organisasi, faktor penentunya adalah kebijakan organisasi, politik organisasi, dan kemampuan membayar organisasi. Ketika keinginan karyawan tidak sesuai dengan kondisi organisasi, yang kemudian muncul adalah ketidakpuasan kerja. Hasil penelitian Darmawan (2015), sistem kompensasi juga punya peran membentuk rasa puas terhadap pekerjaan. Dalam penelitian ini ketidakpuasan kerja dinyatakan karena karyawan merasa kompensasi yang diterima tidak sebanding dengan tanggung jawab dan beban kerjanya. Hasil penelitian menunjukkan bahwa kemampuan keuangan perusahaan kemudian membatasi pemenuhan keinginan karyawan dalam hal peningkatan kompensasi

Pengembangan karir berpengaruh positif terhadap kepuasan kerja karena adanya kesadaran dan kebutuhan setiap karyawan untuk meningkatkan kemampuan diri sebagai bentuk aktualisasi diri dan tanggung jawab terhadap pekerjaan yang dihadapi. Selain itu, teori yang ada sebelumnya menyebut pengaruh pengembangan sistem karir akan dimaksimalkan terhadap kemunculan rasa puas dengan pekerjaan dengan adanya sinergi antara individu, atasan, dan organisasi dalam mewujudkannya. Hasil temuan di studi ini sesuai dengan Kaya dan Ceylan (2014); dan Al Hakim et al. (2019). Kaya dan Ceylan (2014) menjelaskan peran organisasi dalam pengembangan karir. Mereka mengatakan bahwa organisasi yang gagal menerapkan pengembangan karir yang tepat bagi karyawannya akan gagal menciptakan kepuasan kerja. Hal ini merupakan akibat dari ketidaksesuaian antara perencanaan karir yang dimiliki karyawan dengan program pengembangan karir yang dilaksanakan oleh organisasi. 
Kepuasan kerja karyawan akan menciptakan budaya pada diri karyawan untuk selalu bekerja baik. Dengan memiliki sikap ini, manajer sebuah perusahaan akan mudah untuk mengarahkan kerja untuk mencapai tujuan perusahaan. Sehingga peran manajemen untuk memberikan kepuasan pada karyawan dan pemiliki perusahaan dapat berjalan dengan baik.

\section{KESIMPULAN}

Penelitian ini menghasilkan temuan yang menyatakan kepuasan kerja karyawan mendapatkan peran dari kompensasi dan pengembangan karir secara simultan. Begitu juga dengan kompensasi yang memengaruhi kepuasan kerja karyawan secara parsial. Hasil ini juga berlaku untuk pengembangan karir, hasil menunjukkan kepuasan kerja karyawan dipengaruhi oleh peran dari pengembangan karir secara parsial.

Saran yang mampu diberikan adalah sebagai berikut. Manajemen perusahaan perlu melakukan perencanaan system pemberian kompensasi. Kompensasi yang diinginkan oleh karyawan tidak hanya dengan memperoleh gaji tinggi tetapi juga fasilitas yang mampu mendukung kerja karyawan seperti lingkungan yang baik atau fasilitas kesehatan. Kompensasi diatur sesuai dengan kontribusi karyawan kepada perusahaan. Dengan demikian karyawan akan selalu memberikan kontribusi yang baik bagi perusahaan dan selalu merasa puas pada pekerjaan yang telah dilakukan. Hal ini akan meningkatkan target kerja untuk mencapai apa yang diinginkan.

Perlunya perencanaan mengenai pengembangan karir pada perusahaan akan memberikan motivasi kepada karyawan. Saat karyawan telah melakukan pekerjaan sesuai target yang diberikan dan memperoleh peningkatan karir maka karyawan akan merasa dihargai dan pasti akan meningkatkan kepuasan pada diri karyawan tersebut. Sistem pengembangan karir yang bertahap dan sesuai dengan apa yang diberikan karyawan perlu dijelaskan pada saat perekrutan karyawan sehingga karyawan dapat mencapai harapan yang diberikan.

\section{DAFTAR PUSTAKA}

Al Hakim, Y. R., M. Irfan, R. Mardikaningsih, \& E. A. Sinambela. (2019). Peranan Hubungan Kerja, Pengembangan Karir, dan Motivasi Kerja terhadap Kepuasan Kerja Karyawan, Management \& Accounting Research Journal, 3(2), 37-45.

Arifin, S., A. R. Putra, \& C. F. B. Hartanto. (2019). Pengaruh Kompetensi, Kompensasi dan Kepemimpinan terhadap Kinerja Karyawan, Ekonomi, Keuangan, Investasi dan Syariah, 1(1), 23-32.

Bernardin, H. J \& J. E. A. Russell. (2013), Human Resource Management, Sixth. Edition. New York: McGrawHill.

Darmawan, D. (2010). Pengaruh Kompetensi Kerja, Budaya Organisasi, Kepemimpinan dan Kompensasi terhadap Loyalitas Kerja, Jurnal Ilmu Sosial, 4(2), 63-76.

Darmawan, D. (2011). Pengaruh Karakteristik Individu, Kompensasi dan Modal Sosial terhadap Loyalitas Kerja, Jurnal Ilmu Sosial, 5(3), 135-146.

Darmawan, D. (2015). Pengaruh Semangat Kerja, Komitmen Kerja dan Kompensasi terhadap Kepuasan Kerja Pegawai, Metromedia, Surabaya.

Darmawan, D et al. (2020). The Quality of Human Resources, Job Performance and Employee Loyalty, International Journal of Psychosocial Rehabilitation, 24(3), 2580-2592. 
Darmawan, D., E. A. Sinambela, M. Hariani, \& M. Irfan. (2020). Analisis Komitmen Organisasi, Iklim Kerja, Kepuasan Kerja dan Etos Kerja yang Memengaruhi Kinerja Pegawai, Jurnal Bisnis dan Kajian Strategi Manajemen, 4(1), 58-70.

Darmawan, D. \& R. Mardikaningsih. (2021). Kepuasan Kerja: Teori dan Studi Ilmiah. Yayasan Pendidikan Cendekia Muslim, Solok.

Dessler, G. (2015). Manajemen Sumber Daya Manusia, Salemba Empat, Jakarta.

George, J.M., \& Jones, G.R. (2008). Understanding and Managing Organizational Behavior, Pearson Prentice Hall, Upper Saddle River. New Jersey.

Ghazzawi, I. A. (2008). Job Satisfaction among Information Technology Professionals in the US: An Empirical Study. The Journal of American Academy of Business, Cambridge, 13(1), 1-15.

Hutomo, S. \& D. Darmawan. (2011). Optimalisasi Manajemen Sumber Daya Manusia Menuju Keunggulan Bersaing, Jurnal Ilmu Sosial, 5(1), 13-22.

Kaya, C., \& Ceylan Belgin. (2014). An Empirical Study on The Role of Career Development Programs in Organizations and Organizational Commitment on The Job Satisfaction of Employees. American Journal of Business and Management, 3(3), 178-191.

Mardikaningsih, R. (2014). Kinerja Karyawan dan Faktor-Faktor yang memengaruhinya, Jurnal Ilmu Sosial, 7(2), 73-84.

Mohammed, M. U., N. Absar, Z. H. Sikder, \& Balasunda. (2016). Employee Compensation Practice in Industrial Enterprises of Bangladesh: A private and public comparison. PetroleumGas University of Ploiesti Bulletin, Economic Science Series, LXII(IV), 52-60.

Mondy, R. W., \& R. M. Noe. (2005). Human Resources Management. Pearson Prentice Hall, New York.

Praveena, R., B. S. Monica, C. R. Ramababu. (2017). A Study on Impact of Employee Compensation on Employee Commitment. International Journal of Advance Research and Innovative Idea in Education, 2(5).

Saleem, Y., M. R. Kamran, F. Sabir, \& J. Iqbal. (2013). Career Development an Imperative of Job Satisfaction and Career Commitment: Empirical Evidence from Pakistani Employees in Banking Sector. European Journal of Business and Management, 5(21).

Salisu, Jamilu B. (2015). The Impact of Compensation on Job Satisfaction of Public Sector Construction Workers on Jigawa State of Nigeria. The Business and Management Review, 6(4).

Santosa, A. \& D. Darmawan. (2002). Hubungan Kepemimpinan, Budaya Organisasi dan Kinerja Karyawan, Jurnal Ilmu Manajemen, 3(2), 81-92.

Sekaran, U. (2003). Research Methods for Business A Skill-Building Approach. 4th Edition, John Wiley \& Sons, New York.

Sinambela, E. A. (2014). Pengaruh Motivasi, Disiplin dan Lingkungan Kerja terhadap Kepuasan dan Loyalitas Kerja, Jurnal Ilmu Sosial, 7(3), 123-136.

Sinambela, E. A. (2020). Pengaruh Pendidikan, Kompetensi Dan Pengalaman Kerja Terhadap Kepuasan Kerja Karyawan, Jurnal Baruna Horizon, 3(2), 277-285.

Wahyudi, I, D. Bhaskara, D. Darmawan, Hermawan \& N. Damayanti. (2006). Kinerja Organisasi dan Faktor-Faktor Pembentuknya, Jurnal Ekonomi dan Bisnis, 4(2), 95-108. 